\title{
Soziokulturelles Wissen und dessen Vermittlung im Rahmen des Gemeinsamen europäischen Referenzrahmens für Sprachen im DaF Lehrbuch „Wie bitte? A1.1“
}

\section{Yabancı Dil Almanca Ders Kitabı „Wie bitte? A.1.1"nin "Diller İçin Avrupa Ortak Başvuru Metni” Çerçevesinde Sosyokültürel Bilgi ve Aktarımı Açısından İncelenmesi ve Değerlendirmesi}

\author{
Ali Sami AKSÖZI
}

\begin{abstract}
${ }^{1}$ Dr. Öğr. Üyesi, Alman Dili Ĕ̆itimi Anabilim Dal, Eğitim Fakültesi, Çukurova Üniversitesi, Türkiye, asatrans@cu.edu.tr, (https://orcid.org/0000-0003-1515-4144)
\end{abstract}

Geliş Tarihi: 06.09.2020

Kabul Tarihi: 03.03.2021

\section{ZUSAMMENFASSUNG}

In der modernen Gesellschaft und besonders im Berufsleben reicht oftmals eine Fremdsprache zu beherrschen nicht mehr aus. Daher erhöht sich die Bedeutung des Zweitfremdsprachenerwerbs. Trotz herrschender Probleme können wir sagen, dass Deutsch als Fremdsprache in der Türkei seinen Platz als Zweitfremdsprache eingenommen hat. Der Sichtwechsel bezüglich des Lehrens und Lernens einer Fremdsprache, die Aufhebung von Grenzen in Europa sowie die Tatsache, dass eine Fremdsprache ohne ihren soziokulturellen Hintergrund nicht gelehrt werden kann, heben das Bedürfnis landeskundliche und soziokulturelle Elemente der jeweiligen Fremdsprache zu vermitteln hervor. In Bezug auf den auch im „Gemeinsamen europäischen Referenzrahmens für Sprachen“ angesprochenen und besonders hervorgehobenen Punkt der soziokulturellen Kompetenz richtet dieser Artikel seinen Focus auf das verbreitet eingesetzte Lehrbuch „Wie bitte? A1.1“ des türkischen Bildungsministeriums, um die Vermittlung von soziokulturellem Wissen im Rahmen des „Gemeinsamen europäischen Referenzrahmens für Sprachen" (GER) zu analysieren und festzustellen in wie weit die im GER angesprochenen Bereiche abgedeckt werden und welche Mängel vorhanden sind.

Schlüsselwörter: Deutsch als Fremdsprache (DaF), Fremdsprachenunterricht, Lehrbücher, Soziokulturelle Kompetenz, Gemeinsamer Europäischer Referenzrahmen (GER).

\section{ÖZ}

Gerek dünyada gerekse Türkiye'de en az bir yabancı dil bilmek günümüzde artık en asgari olması gereken bir durumdur ve özellikle iş hayatında sadece bir tane yabancı dil bilmek artık yeterli değildir. Bu bağlamda ikinci yabancı dil öğretimine de ayrı bir değer verilmesi gerektiği sonucu ortaya çıkmaktadır. Almanca açısından baktı̆̆ımızda Türkiye'de ikinci yabancı dil olarak yerini aldığını ve İngilizceye göre daha az önem verildiği görülmektedir. Globalleşen dünya kapsamında gerek fiziksel gerekse toplumsal sınırların giderek kaybolması yabancı dil öğretiminde de kültürlerarasılık boyutunu ön plana çıkarmaktadır. Yabancı dil öğretimi sadece dilbilgisel yapıların ve sözcük dağarcığının aktarımı ile gerçekleşmemektedir. Günümüzde yabancı dil öğretimi aynı zamanda söz konusu dilin konuşulduğu ülkeye ilişkin ülke bilgisi, toplum yapısı ve kültür aktarımını da zorunlu hâle getirmektedir. Diller toplum içerisinde gelişip değiştiği için, bu boyutun da yabancı dil öğretiminde dikkate alınması gerekmektedir. Bu makalede, "Diller için Avrupa Ortak Başvuru Metni”nde de önemi vurgulanan sosyokültürel öğeler ve bunların yabancı dil öğretimindeki aktarımı boyutu, bahsi geçen başvuru metnine uygun olarak hazırlandığı beyan edilen Milli Eğitim Bakanlığı tarafından yayınlanmış olan ikinci yabancı dil Almanca „Wie bitte? A1.1“ adlı ders kitabı, 
sosyokültürel öğeler açısından incelenmiştir. "Wie bitte? A1.1" ders kitabında, sosyokültürel öğelere ne kadar yer verildiği, herhangi bir Avrupa ülkesinin sosyokültürel özellikleri kapsamında ortak başvuru metninde belirtilen noktalardan hangilerinin kitapta yer bulduğuna ilişsin bir inceleme gerçekleştirilmiştir.

Anahtar Kelimeler: Yabancı dil olarak Almanca, yabancı dil dersi, ders kitapları, sosyokültürel yeti, diller için Avrupa ortak başvuru metni.

\section{EINLEITUNG}

In unserem Zeitalter ist es zu einer Selbstverständlichkeit geworden mindestens eine Fremdsprache zu beherrschen, wobei eine Fremdsprache im Berufsleben oftmals nicht mehr ausreicht. In dieser Hinsicht sollte dem Zweitfremdsprachenerwerb eine größere Bedeutung zugesprochen werden. Bezüglich des DaF-Unterrichts, der in der Regel in der Türkei hinter dem Englischen als Zweitfremdsprache seinen Platz einnimmt, ist zu erwähnen, dass er neben den allgemeinen Problemen, die beim Erlernen einer Fremdsprache auftreten, auch unter einem Stiefkind-Syndrom leidet. Ihm wird weniger Achtung geschenkt oder sogar als störend empfunden (vor allem in den oberen Klassen). Dies spiegelt sich besonders in der Betrachtungsweise der Behörden, im Curriculum sowie den Lehrbüchern wieder, was in manchen Regionen besonders zu spüren ist (vgl. Umut Balc1, 2017). Kırmız1 (2009: 268) deutet darauf hin, dass auch unter den Lernenden Vorurteile gegenüber dem DaF-Unterricht herrschen und ein Motivationsmangel vorhanden ist, dessen Gründe auf die mangelnde Zielbeschreibung des DaF-Unterrichts und dessen Bedeutung und Funktion zurückzuführen sind. Jedoch wird dieser Prozess auch durch die mangelnde Konzeption der Lehrbücher verstärkt. In diesem Zusammenhang ist auch die Annäherung an die Kultur der Zielsprache, deren Bekanntmachung sowie die Darbietung von Reflexionsmöglichkeiten, die früher außer Acht gelassen wurden, von großer Bedeutung. Daher richtet sich dieser Artikel an das verbreitet eingesetzte Lehrbuch des türkischen Bildungsministeriums „Wie bitte? A1.1“ (Öztürk, D., Incebel, F., Balkan, F., Yıldırım, T., Canoğlu, Y., 2019) um die Vermittlung von soziokulturellem Wissen im Rahmen des „Gemeinsamen europäischen Referenzrahmens für Sprachen“ (GER) zu analysieren und festzustellen in wie weit die im GER angesprochenen Bereiche abgedeckt werden.

\section{ZUR BEDEUTUNG SOZIOKKULTURELLEN WISSENS}

Während früher der Fremdsprachenunterricht stark grammatisch geprägt war, hat sich mit der Zeit das Verständnis, wie eine Fremdsprache zu lehren ist, verändert und gegenwärtig treten kommunikative und interkulturelle Bestreben in den Vordergrund. Eine Fremdsprache zu lernen bedeutet auch mit einer neuen Gesellschaft, deren Normen und Kultur zu begegnen. Sprachen sind eng von der Gesellschaft und dessen Kultur, in der sie gesprochen werden, geprägt. Mohammed (2019:1) erklärt hierzu: „Das Beherrschen einer Fremdsprache allein reicht nicht aus, um mit den Menschen der Zielsprache richtig kommunizieren sowie deren alltäglichen Verhaltensweisen verstehen zu können“ und erläutert weiter, dass der Fremdsprachenunterricht Informationen über die Kultur und die Gesellschaft des jeweiligen Landes vermitteln und neben der Fremdsprache auch zum Erlernen und verstehen der Zielkultur führen soll (Ebd). Dies bedeutet nicht nur die passive Vermittlung und Beherrschung landeskundlichen Wissens der Zielsprache, sondern der Lerner sollte dadurch auch befähigt werden seine eigene Kultur in einem neuen Blickwinkel zu betrachten und zwischen Kulturen vergleichen können. In diesem Zusammenhang erklären Marques-Schäfer, Filho und Stanke „Im interkulturellen Fremdsprachenunterricht sollen Lernende mehr als nur die fremde Sprache lernen. Sie sollen durch die Sprache die fremde Kultur kennenlernen und nicht nur die neue fremde Kultur reflektieren, sondern auch die eigene“ (2016: 568). Daher erfordert der gegenwärtige Fremdsprachenunterricht auch die Vermittlung soziokultureller Elemente, da sie wichtige Bestandteile zur Entschlüsselung kommunikativer Mitteilungen, Handlungen und Haltungen sind, was uns zu dem im GER genannten Begriff mehrsprachige 
und plurikulturelle Kompetenz führt, die als „die Fähigkeit, Sprachen zum Zweck der Kommunikation zu benutzen und sich an interkultureller Interaktion zu beteiligen" (GER, 2001: 163) beschrieben und der „Mensch als gesellschaftlich Handelnder verstanden wird, der über graduell unterschiedliche - Kompetenzen in mehreren Sprachen und über Erfahrungen mit mehreren Kulturen verfügt" (Ebd.). Um Handlungen hervorrufen zu können, sollte die Vermittlung soziokultureller Elemente in Aktivitäten eingebettet sein, Diskussionsanlässen Platz gegeben werden. Damit mehr oder weniger ein Standard in diesem Bereich erzielt werden kann, steht die Vermittlung dieser Kompetenz vor allem im Aufgabenbereich der Lehrbücher.

\section{LEHRBÜCHER UND SOZIOKULTURELLE ELEMENTE IM FREMDSPRACHENUNTERRICHT}

Lehrbücher, die ein wichtiger Bestandteil des Fremdsprachenunterrichts sind, haben die Aufgabe neben Grammatik, Wortschatz etc. auch die jeweilige Kultur der zu erlernenden Fremdsprache $\mathrm{zu}$ vermitteln. Während früher davon ausgegangen wurde, dass eine Fremdsprache durch Grammatik zu erlernen sei, hat sich heute die Betrachtungsweise des Fremdsprachenlehrprozesses verändert. Im gegenwärtigen Fremdsprachenunterricht sind die kommunikativen und interkulturellen Seiten wichtige Bestandteile des Fremdsprachenlehr/lernprozesses. Die Sprache ist kein statisches Objekt und verändert sich in der jeweiligen Gesellschaft mit der Zeit. Wie auch Memiş (2016: 605) betont, entwickeln und formen sich Sprache und Gesellschaft gemeinsam. Um eine Fremdsprache richtig zu erlenen und zu beherrschen reicht daher die Vermittlung von sprachlichen Mitteln und der Grammatik nicht aus. Zur richtigen Interpretation kommunikativer Situationen ist auch die Vermittlung von kulturellen Elementen wichtig. Neben landeskundlichem Wissen sind auch kulturelle Handlungen, sprachliche Elemente zu vermitteln. Auch Storch (2009: 28) betont die Notwendigkeit der Vermittlung von landeskundlichen und soziokulturellen Elementen und beschreibt diese folgendermaßen:

Im DaF-Unterricht sollen die Lernenden ein explizites Wissen in den folgenden Bereichen erwerben:

- ein landeskundliches Wissen über „Land und Leute“ der deutschsprachigen Länder

- ein soziokulturelles Wissen, das sie dazu befähigt sich in einem deutschsprachigen Land situations- und partnergerecht adäquat zu verhalten und wichtige Aspekte des Alltagsverhaltens der Menschen in den deutschsprachigen Ländern adäquat einzuschätzen.

Desweiteren ergibt sich auch aus Sicht der Emotionalen Lerngegenstände und Lernziele (vgl. Storch, 2009: 25) die Notwendigkeit soziokulturelle Elemente zu vermitteln, da im Fremdsprachenunterricht eine positive Haltung gegenüber der zu erlernenden Fremdsprache entwickelt und gefördert werden soll. Je mehr der Lernende über die Gemeinsamkeiten und Unterschiede zwischen seiner und der Zielkultur erfährt, die Unterschiede versteht und zu respektieren lernt, desto positiver wird seine Haltung gegenüber der Zielsprache.

Als Ziele eines interkulturellen Fremdsprachenunterrichts werden von Marques-Schäfer, Filho und Stanke (2016: 567f) folgende Punkte genannt: „(i) das Kennenlernen einer fremden Kultur; (ii) die Reflexion über die eigene und über die fremde Kultur; (iii) die Entwicklung einer Sensibilität für Gemeinsamkeiten undUnterschiede zwischen der eigenen und der fremden Kultur und (iv) die Förderung eines Perspektivenwechsels. “ Aus diesen Zielen geht hervor, dass eine passive Vermittlungsweise nicht ausreicht und diese Elemente handlungs/produktionsorientiert, Kontextgebunden und vergleichend vermittelt werden sollten. Sie müssen daher in einem Kontext gebunden logisch präsentiert werden und durch Aktivitäten sollte der Lernende dazu verleitet werden nachzudenken, zu reflektieren und zu diskutieren. Damit im gegebenen Fall richtige Inferenzen gebildet werden können und Missverständnissen 
vorgebeugt werden kann. Dies bezieht sich besonders auf elaborative Inferenzen, zu deren richtigen Bildung das nötige Hintergrundwissen benötigt wird (vgl. Nebe-Rikabi, 1997). Denn nur durch eine angemessene Vermittlung von soziokulturellen Elementen kann der Lernende befähigt werden sprachliche Handlungen und Verhaltensweisen richtig zu interpretieren, sich an ihnen $\mathrm{zu}$ beteiligen und entsprechend zu reagieren.

\section{SOZIOKULTURELLES WISSEN NACH DEM GEMEINSAMEN EUROPÄISCHEN REFERENZRAHMEN FÜR SPRACHEN}

Im gemeinsamen europäischen Referenzrahmen für Sprachen werden unter den praktischen Fertigkeiten soziale Fertigkeiten genannt, die als ,die Fähigkeit, sich entsprechend den in Abschnitt 5.1.1.2 dargestellten Konventionen zu verhalten und die erwarteten Routinen auszuführen..." erläutert werden. Im angesprochenen Abschnitt 5.1.1.2 werden als charakteristische Merkmale einer bestimmten europäischen Gesellschaft und Kultur folgende Punkte genannt (GER, 2001: 104f):

1. das tägliche Leben, umfasst Bereiche wie Essen und Trinken, Essenszeiten, Tischmanieren; Feiertage; Arbeitszeiten und -gewohnheiten; Freizeitbeschäftigungen (Hobbys, Sport, Lesegewohnheiten, Medien).

2. Lebensbedingungen, umfasst Bereiche wie den Lebensstandard (mit regionalen, schichtspezifischen und ethnischen Abweichungen); Wohnverhältnisse; soziale Absicherung.

3. interpersonale Beziehungen, in Bezug auf: die schichtspezifische Struktur einer Gesellschaft und Beziehungen zwischen sozialen Gruppen; Beziehungen zwischen den Geschlechtern (männlich/weiblich, Grad der Vertrautheit); Familienstrukturen und beziehungen; Beziehungen zwischen den Generationen; Beziehungen in Arbeitssituationen; Beziehungen zwischen Öffentlichkeit und Polizei, Verwaltung usw.; Beziehungen zwischen ethnischen und anderen Bevölkerungsgruppen; Beziehungen zwischen politischen und religiösen Gruppierungen.

4. Werte, Überzeugungen und Einstellungen in Bezug auf Faktoren wie: die soziale Schicht; Berufsgruppen (Akademiker, Management, Beamte, gelernte und ungelernte Arbeiter); Vermögen (verdient und ererbt); regionale Kulturen; Sicherheit; Institutionen; Tradition und sozialer Wandel; Geschichte; insbesondere herausragende historische Persönlichkeiten und Ereignisse; Minderheiten (ethnische, religiöse); nationale Identität; andere Länder, Staaten, Völker; Politik; Kunst (Musik, bildende Künste, Literatur, Drama, populäre Musik und Lieder); Religion; Humor.

5. Körpersprache (vgl. Abschnitt 4.4.5.2): Die Kenntnis der die Körpersprache regulierenden Konventionen stellt einen Teil der soziokulturellen Kompetenz der Sprachverwendenden/Lernenden dar.

6. Soziale Konventionen, z. B. in Bezug auf das Verhalten von Gast und Gastgeber: Pünktlichkeit; Geschenke; Kleidung; Erfrischungen, Getränke, Mahlzeiten; Konventionen und Tabus in Benehmen und Unterhaltung; Dauer des Besuchs; sich verabschieden.

7. rituelles Verhalten in Bereichen wie: religiöse Bräuche; Geburt, Heirat, Tod; Verhalten von Zuschauern bei öffentlichen Veranstaltungen und Zeremonien; Feierlichkeiten, Festivals, Tanzveranstaltungen, Diskotheken usw.

In GER wird betont, dass diesen eine besondere Aufmerksamkeit zu schenken ist, weil sie für den Lernenden wichtig sind und ,weil es im Gegensatz zu vielen anderen Wissensaspekten sehr wahrscheinlich außerhalb des früheren Erfahrungsbereichs des Lernenden 
liegt und zudem durch Stereotypen verzerrt sein kann“" (GER, 2001: 7). In Anlehnung an GER wird auch im Lehrprogramm für Deutsch des türkischen Bildungsministeriums (vgl. MEB, 2018) sowohl in den Lernzielen als auch in den Kriterien für die Lehrwerkerstellung die Bedeutung soziokultureller Elemente angesprochen und deren Vermittlung gefordert.

Es wird angestrebt diese Punkte während des Fremdsprachenerwerbsprozesses angemessen zu vermitteln. Der Begriff „,angemessen“ bezieht sich hier nicht nur auf die zu vermittelnden Themen bzw. soziokulturellen Elemente, sondern auch darauf, dass diese im Hintergrund kontextgebunden zu vermitteln sind und bei den Lernenden gegebenenfalls ein „Aha-Effekt" erzeugt wird. Bei vielen Bestrebungen -wie z.B. beim Einsatz neuer Medien, literarischer Texte etc.- geschieht es oftmals, dass diese sich unbemerkt in den Vordergrund drängen und auf einmal zum Zweck/Ziel des Fremdsprachenunterrichts mutieren. Es geht nicht darum einen Erdkundeunterricht durchzuführen, sondern dieses Wissen sollte in den jeweiligen Themenkreis eingebettet, kontextgebunden und Funktionserfüllend präsentiert werden, um der auch von Kirmız1 (2009: 269) angesprochenen Forderung eines effektiven, ungebundenen Fremdsprachengebrauchs gerecht zu werden.

Wie zuvor schon erläutert ist die Vermittlung soziokultureller Elemente auch bezüglich der Haltung der Lerner gegenüber der Zielsprache wichtig, da ein verzerrtes Bild von der Kultur und Gesellschaft der Zielsprache die Haltung der Lernenden beeinträchtigen und sich im Lernprozess negativ auswirken kann. Z.B. wie viele Lerner würden motiviert eine Zielsprache lernen wollen, über deren Gesellschaft und Kultur sie negative Gefühle empfinden?

Es gibt verschieden Kriterienkataloge und Studien zur Untersuchung der Vermittlung von Landeskunde und kulturellen Elementen im Fremdsprachenunterricht und in Lehrbüchern (siehe Tomkova, 2007; Cuma, 2009; Saraç, \& Arıkan, 2010; Koçak, 2014; Köşker, 2015; Memiş, 2016; Sakarya Maden, Kula, Çalışkan, 2017). Weil das Lehrbuch „Wie bitte? A1.1“ sich nach dem GER richtet, werden bei der Analyse die oben angegebenen Punkte als Kriterien verwendet, um festzustellen in wie weit Informationen über diese Bereiche im Buch vorhanden sind und welche Bereiche abgedeckt werden.

Bezüglich der Anwendung vorhandener Kriterienkataloge und durchgeführten Studien zur Kulturvermittlung in Lehrwerken sehe ich die Schwäche darin, dass oftmals die vorgesehenen Kriterien pauschal angewendet werden. D.h. die Lehrwerke werden analysiert und durchgesehen, ob die jeweiligen Punkte der Kriterien erfüllt werden. Jedoch ist der Fremdsprachenerwerb ein langjähriger Prozess und man sollte von einem Lehrwerk, das z.B. für die Anfängerstufe vorgesehen ist, nicht erwarten, dass es alle Kriterien auf ein Mal erfüllt. Es sollte in Betracht gezogen werden für welchen Zeitraum, für welches Niveau das Lehrbuch vorgesehen ist, in welcher Situation sich der jeweilige Fremdsprachenunterricht befindet, durch welche bildungspolitischen Ziele und Autozensuren das Lehrbuch geformt wird. Weiter sollte auch beachtet werden, ob im jeweiligen Themenkreis Niveauentsprechende kulturelle Elemente der Zielgruppe angemessen präsentiert bzw. vermittelt werden. Eine wichtige Frage ist für welches Niveau welche kulturellen Elemente vermittelt werden sollen. Es bedarf in dieser Hinsicht tiefergreifende Studien und Kriterienkataloge.

\section{ZUM LEHRWERK „WIE BITTE? A1.1“}

„Wie bitte? A1.1“ ist eines der Hauptlehrwerke, das an den sozusagen allgemeinen Schulen für Deutsch als Zweitfremdsprache eingesetzt wird. Es ist ein vom türkischen Bildungsministerium in Auftrag gegebenes und veröffentlichtes DaF-Lehrwerk, das besonders an Schulen in denen DaF als Zweitfremdsprache mit 2 Stunden in der Woche stattfindet und wenn man das so sagen darf- die Zweitfremdsprache als Nebensache betrachtet wird, bevorzugt wird, weil es einfach aufgebaut ist und kostenlos vom türkischen Bildungsministerium bereitgestellt wird. Das Lehrwerk besteht aus einem Lehrbuch, Arbeitsbuch und Lehrerhandbuch, wobei das Lehrerhandbuch nichts weiter als ein Lösungsschlüssel fungiert. 
Weder didaktische Vorschläge, alternative Vorgehensweisen noch Erweiterungsmöglichkeiten für den Unterricht werden geboten. Weiter wird „Wie bitte? A1.1“ auch in der Fernschule (açık öğretim lisesi) eingesetzt. Daher kommen dem Lehrbuch auch weitere Aufgaben zu. Während im Klassenzimmer der Lehrer manches ausgleichen, ergänzen kann, ist in der Fernschule dies nicht möglich. Daher sollte das Lehrbuch auch in der Lage sein die fehlende Präsenz des Lehrers auszugleichen.

Die Bewertungen der soziokulturellen Elemente richten sich nach den im Referenzrahmen angegebenen Merkmalen und es wird auch beachtet, ob das notwendige Wissen in den jeweiligen Themenkreisen im Buch platzfindet. Bei der Analyse wurde versucht den Status und die Situation, in der sich der DaF-Unterricht als Zweitfremdsprache befindet, nicht aus den Augen zu verlieren und das Lehrbuch dementsprechend zu bewerten.

\section{SOZIOKULTURELLES WISSEN IN „WIE BITTE? A1.1“}

\subsection{Das tägliche Leben}

Das tägliche Leben umfasst verschiedene Unterpunkte wie Essen und Trinken, Mahlzeiten, Tischmanieren, Feiertage, Arbeitszeiten und -gewohnheiten, Freizeitbeschäftigungen. Zum täglichen Leben der Deutschen werden in „Wie bitte? A1.1“ verschiedene Unterpunkte behandelt und während manche Bereiche verhältnismäßig recht gut abgedeckt werden, werden manchen kulturell wichtigen Punkten überhaupt keine Achtung geschenkt.

Zum alltäglichen Leben der Lernenden gehören zum größten Teil auch die Schule und der Schulalltag. Im Lehrbuch werden in den jeweiligen Modulen die Schule und der Schulalltag an deutschen Schulen präsentiert. Aus den Bildern, von denen wir ausgehen, dass sie aus Deutschland stammen, sind Informationen zu diesem Bereich zu entnehmen und die Lernenden können dies mit ihrem eigenen Schulwesen vergleichen, Gemeinsamkeiten und Unterschiede entdecken.

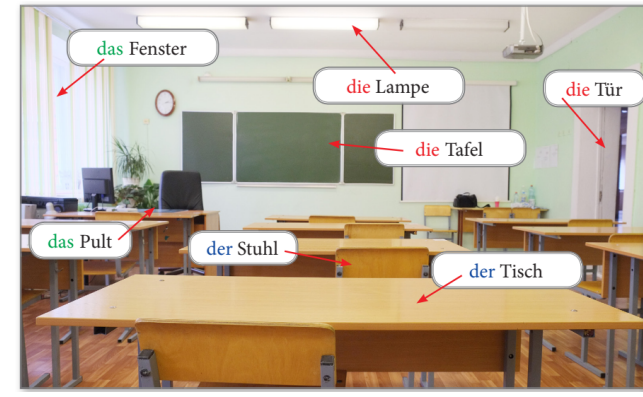

Abb.1 Abbildung eines Klassenzimmers

(Öztürk et al., 2019: 22)

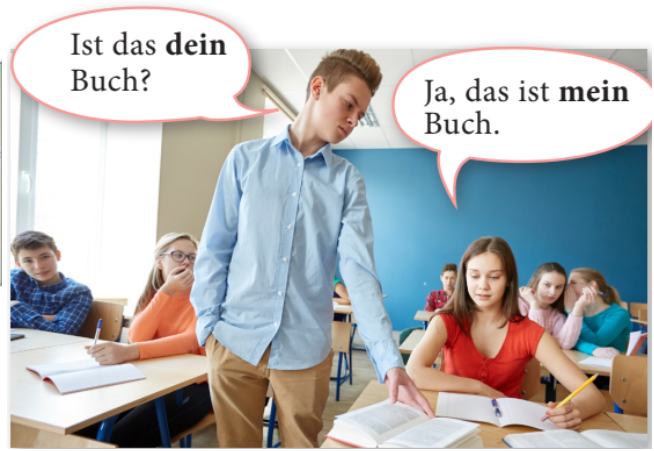

Abb.2 Schüler in der Klasse

(Öztürk et al., 2019: 23)

In Abbildung 1 wird ein Klassenzimmer gezeigt, anhand dessen die Lernenden ihr eigenes Klassenzimmer vergleichen können und Abbildung 2 zeigt Schüler in der Klasse. Aus diesem Bild und weiteren Bildern ähnlicher Art wird für die Lernenden z.B. ersichtlich, dass es in Deutschland keine Schuluniform gibt. In „Modul 2“ werden eine Reihe von Bildern präsentiert, aus denen die Kleidung der Schüler ersichtlich ist. Dies könnte -wenn auch in der Muttersprache- zu einer Diskussion anregen und den Vergleich zwischen den Schulen in der Türkei und Deutschland vertiefen. Bezüglich des Wortschatzes sehen wir z.B., dass die Abkürzung für Kugelschreiber, Mathematik angegeben wurden. Dies ist positiv zu bewerten, da im Alltag eher die Abkürzung „Kuli“ und „Mathe“ benutzt wird. Zum Thema Schulalltag, - 
ablauf, Fächer etc. können wir sagen, dass niveaumäßig der notwendige Wortschatz vermittelt wird.

\begin{tabular}{|c|c|c|c|c|c|}
\hline \multicolumn{6}{|c|}{ Stundenplan } \\
\hline & Montag & Dienstag & Mittwoch & Donnerstag & Freitag \\
\hline 1. Stunde & Biologie & & Englisch & Englisch & Mathematik \\
\hline 2. Stunde & Biologie & & Englisch & & Mathematik \\
\hline 3. Stunde & & sport & Dentsch & & \\
\hline 4. Stunde & Deutsch & sport & Geschichte & Physik & \\
\hline 5. Stunde & Dentsch & Mathematik & Geschichte & Deutsch & sport \\
\hline 6. Stunde & Physik & Englisch & & Dentsch & sport \\
\hline 7. Stunde & - & Musik & 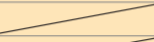 & Kunst & $\infty$ \\
\hline 8. Stunde & 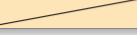 & Musik & 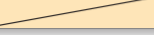 & Kunst & 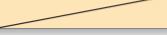 \\
\hline
\end{tabular}

Abb.3 Stundenplan (Öztürk et al., 2019: 25)

Abbildung 3 zeigt einen Stundenplan, aus dem die Lernenden an deutschen Schulen unterrichtete Fächer entnehmen und mit ihrem eigenen Stundenplan vergleichen können. In diesem Modul sind auch Texte vorhanden, anhand derer der Schulalltag, die Fächer vermittelt werden. Im Text „Stefans Schulalltag“ (Modul 2B3a) (Öztürk et al., 2019: 25) werden neben den Fächernamen auch Gefühlsausdrücke und Konventionen in Benehmen und Unterhaltung bezüglich der Anrede von Lehrern vermittelt.

„Modul 2C“ widmet sich dem außerunterrichtlichen Bereich in der Schule und deckt auch den Bereich Freizeitbeschäftigung ab. Hier wird der Begriff Arbeitsgemeinschaft (AG) nähergebracht und die Lernenden erfahren, was deutsche Schüler außerhalb des Unterrichts in der Schule machen können.

Die Arbeitsgemeinschaften (AG)

Schau dir die Fotos an und ordne die Verben zu!

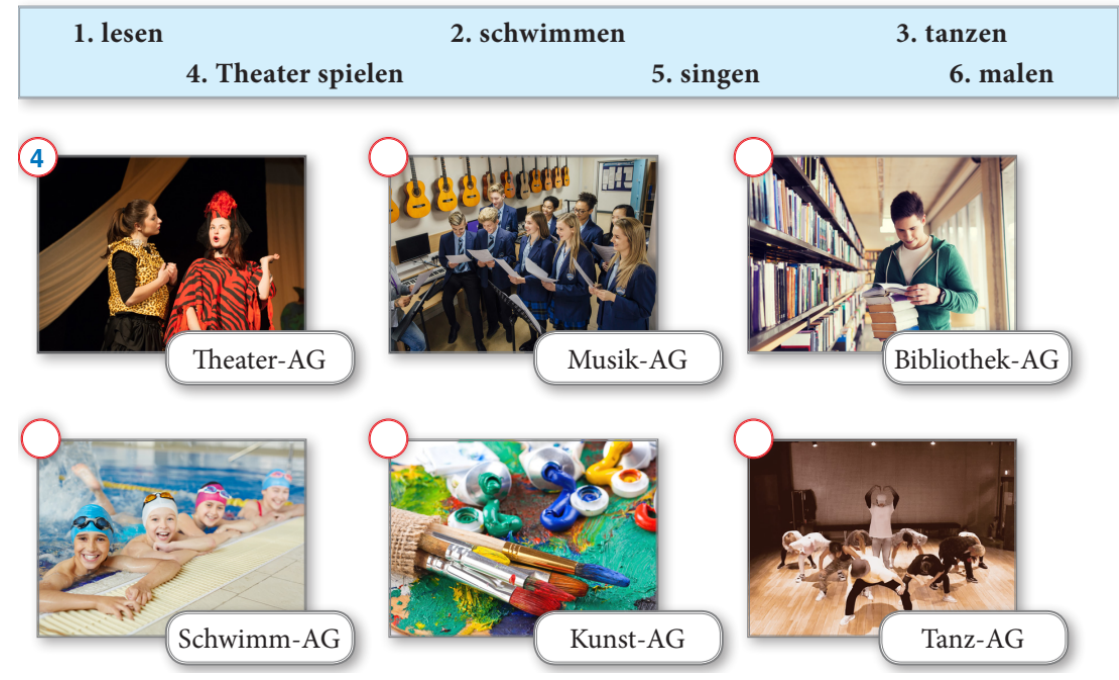

Abb.4 Beschäftigungen zum außerunterrichtlichen Bereich (Öztürk et al., 2019: 26)

Anhand der Bilder können die Lernenden vermuten und identifizieren, welche AGs es gibt. Weil es in der Türkei auch ähnliches gibt, wird es ihnen nicht schwer fallen diese zu semantisieren. Auch wenn die Gleichstellung des türkischen „eğitsel kol“" mit AG nicht ganz übereinstimmt, bietet dieses Modul wiederum eine Diskussionsmöglichkeit, um die türkischen Schulen und deutschen Schulen zu vergleichen, weitere Gemeinsamkeiten bzw. Unterschiede zu entdecken. Je mehr Gemeinsamkeiten die Lernenden entdecken, desto weniger wird die Abneigung zu der Zielkultur und folglich auch zu der Zielsprache sein. 
„Modul 7“ beschäftigt sich im Allgemeinen mit Freizeitaktivitäten und Hobbys. Hier wird thematisiert was (deutsche) jugendliche in ihrer Freizeit machen, welche Hobbys sie haben. Es werden neben allgemeinen Aktivitäten auch eher typisch deutsch (vgl. Typisch deutsch: Fußball, Bier und Wandern?, 2017, 10. August) zu bezeichnende Aktivitäten wie z.B. „Wandern“ genannt. Was ein Teil der deutschen Kultur (siehe https://www.wanderverband.de) und in dem Ausmaß in der Türkei nicht vorhanden ist.

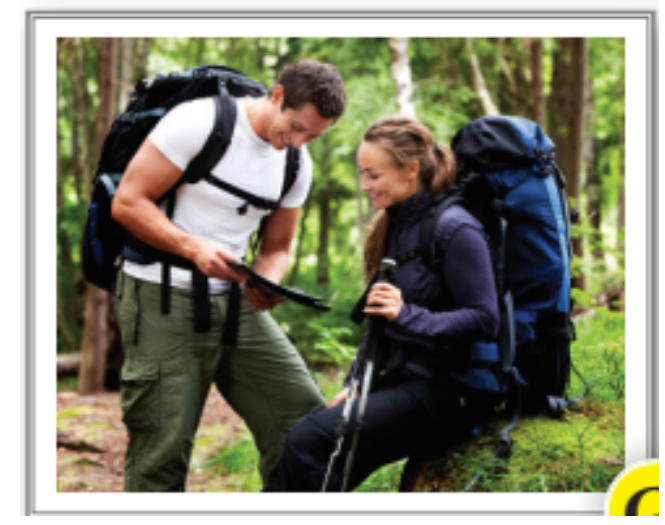

Abb.5 Abbildung zu Wandern (Öztürk et al., 2019: 72)

Aus der obigen Abbildung wird auch für die Lernenden ersichtlich, was unter wandern zu verstehen ist und nicht ein einfacher Spaziergang in der Natur gemeint ist.

In Modul 7C3a (Öztürk et al., 2019: 77) wird unter anderen Aktivitäten „Bücher lesen“ genannt. Diese Bezeichnung ist eher türkisch gedacht. Bei der Benennung dieser Aktivität als Hobby wird in der Regel nur „Lesen“ geschrieben.

\subsubsection{Feiertage}

Unter den Bereich tägliches Leben fallen auch Feiertage und Feste. In „Wie bitte? A1.1“ trägt Modul6 den Namen „Besondere Tage“ und erweckt die Erwartung, dass hier besondere Tage der Zielsprache also der deutschen Kultur behandelt werden. Jedoch werden bezüglich der Besonderen Tage nur Weihnachten und Silvester genannt.

\section{Feste und Feiertage}

a Schreib das Datum von den angegebenen Festen und Feiertagen!

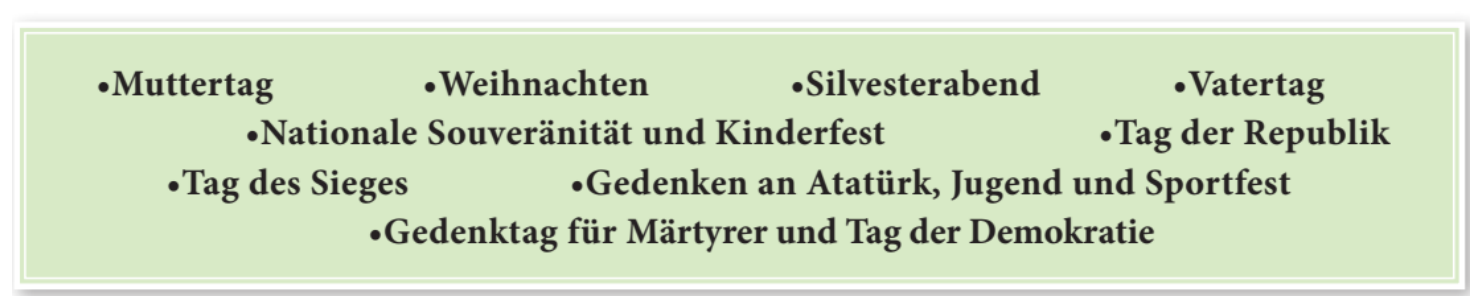

Abb.6 Übung zu Festen und Feiertagen (Öztürk et al.: 63)

In der oben abgebildeten Übung wird von den Lernenden verlangt das Datum der jeweiligen Tage zu recherchieren und zu schreiben. Positiv ist hier zu bemerken, dass die Verwechslung zwischen Weihnachten und Silvester aufgeklärt werden kann. Jedoch sehen wir, dass sich die Feiertage eher auf türkische fokussieren und nicht die der Zielkultur. Dieser Umstand macht sich im ganzen Modul bemerkbar. Tag der Einheit, Rosenmontag, Fasching, Karneval, Ostern etc. werden nicht mal genannt geschweige denn thematisiert zu werden. Sei es nun aus bildungspolitischen Gründen oder anderen, in diesem Bereich schwächelt „Wie bitte? A1.1" sehr. Gegen herrschende Missverständnisse wie z.B. die Funktion des Weihnachtsbaums, der zum Neujahrsbaum mutiert wurde, wird nichts unternommen. 
Auffallend ist auch, dass in den Modulen keine Abbildung (außer dem Foto von Ostereiern im Landeskundeteil) bezüglich der deutschen Feiertage und Fest im Lehrbuch zu finden sind und diesen keine Beachtung geschenkt wurde.

\subsubsection{Essen und Trinken, Essenszeiten, Tischmanieren}

Während Modul 5 in „Wie bitte? A1.1“ als Hauptthema „Essen und Trinken“ behandelt und zu erwarten ist, dass in diesem Modul soziokulturelles Wissen in diesem Bereich behandelt wird, sind auch in anderen Modulen zu diesem Thema Elemente zu finden. So wird z.B. in Modul 4 der Tagesablauf thematisiert und ein Bild von einem Frühstück angezeigt.

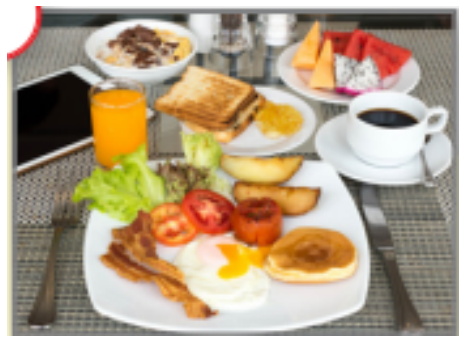

Abb.7 Foto eines Frühstücks (Öztürk et al., 2019: 42)

Auf Abbildung 7 ist ein amerikanisches Frühstück mit Bacon, Eiern, Pancakes zu erkennen. Um im Hintergrund die notwendigen Informationen bezüglich der deutschen Kultur zu liefern, hätte die Bildauswahl sorgfältiger ausfallen müssen. Durch Abbildung eines typisch deutschen Frühstücks mit Brot/Brötchen, Aufstrich, Käse, Wurst wäre für die Lernenden ersichtlich geworden, wie die Deutschen frühstücken und was sie essen.

Eine ähnliche Nachlässigkeit ist bei der Abbildung einer Torte und deren Benennung als Kuchen zu sehen.

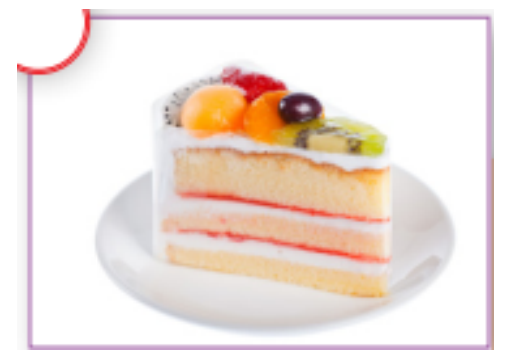

Abb.8 Foto einer Torte (Öztürk et al., 2019: 46)

Es mag nun sein, dass der Begriff „Kuchen“ als Oberbegriff angewendet wurde, aber die Deutschen unterscheiden zwischen den Begriffen „Kuchen“ und „Torte“ und benutzen sie auch dem entsprechend. Hier wurde meines Erachtens versäumt den Unterschied zwischen beiden Begriffen klarzustellen. In dieser Übung (Modul 4C1c: 46) hätte man einfach ein Foto von einem Kuchen hinzufügen und anhand der Bilder hätten die Lernenden den Unterschied auch selbst entdecken können. So wäre es möglich gewesen das notwendige Wissen im Hintergrund zu vermitteln.

Im Lehrbuch werden aber auch einige spezifisch deutsche Begriffe und Gegebenheiten angegeben. Z.B. die Mengenangabe „Pfund“, die es im türkischen nicht gibt. Auch die Gegebenheit, dass Wassermelonen in Scheiben gekauft werden, was in der Türkei nicht üblich ist, sowie das „Abendbrot“ präsentieren Elemente der deutschen Kultur. Wobei die Abbildung des Abendbrots recht mager ausgefallen ist, um die kulturelle Ebene hervorzuheben hätte hier ein richtig traditionelles Abendbrot abgebildet werden können.

In Modul 5, das sich hauptsächlich mit dem Thema „Essen und Trinken“ beschäftigt wird als deutsches Gericht das Rezept des Kartoffelsalats (Öztürk et al., 2019: 57) angegeben. Das 
Rezept entspricht einem typisch deutschen Kartoffelsalat und präsentiert auch angemessen einen Hauch deutscher Kultur. Im Gegensatz zu diesem guten Beispiel ist der Text mit „Einkaufen im Supermarkt" (Öztürk et al., 2019: 54) wo ein Fischgericht als Beispiel gegeben wird keine gute Auswahl, da es eher das englische Gericht „fish and chips“ suggeriert. Hier spiegelt sich auch eine nachlässige Auswahl des Bildes, da im Text von Kochen „Meine Mutter kocht den Fisch und die Kartoffeln“ (Ebd.) die Rede ist und ein gebratener/gegrillter Fisch sowie Bratkartoffeln abgebildet werden. Während z.B. der Unterschied zwischen Kellner und Ober für diese Niveaustufe zu kompliziert oder überflüssig wäre und daher auch gut ist, dass es im jeweiligen Modul (4C, Öztürk et al., 2019: 46f) nicht vertieft wurde, ist für backen/braten oder kochen die Erklärung recht einfach, da es auch entsprechende Bezeichnungen im Türkischen gibt. Aus meiner langjährigen Erfahrung, kann ich sagen, dass die Gleichsetzung unterschiedlicher Begriffe (z.B. kochen/braten/backen oder Torte/Kuchen) im weiteren Lauf des Fremdsprachenerwerbs zu Problemen führt und die Begriffe von den Lernenden immer wieder falsch benutzt werden. Als typisch deutsches Fischgericht hätte man auch Fischfilet mit Rahmspinat angeben können. Ein interessantes Beispiel wären Maultaschen gewesen, um den Vergleich mit „Mantı“ zu ermöglichen.

\subsubsection{Lebensbedingungen}

Aus den Fotos im Lehrbuch sind gewissermaßen die Lebensbedingungen und der Lebensstandard der Deutschen zu erkennen. Jedoch werden die Wohnverhältnisse nicht thematisiert. Es gibt keinerlei Abbildungen oder Texte zu einer deutschen Wohnung, zu einem Jugendzimmer. Der Frage „Wie leben Deutsche?“ wird nicht näher eingegangen und thematisiert. Die Lernenden können durch die Aktivitätsmöglichkeiten und Hobbys interpretieren wie der Lebensstandard ist, aber sehen nicht wie der deutsche Jugendliche lebt, wie sein Zimmer ist, welche Wohnverhältnisse in Deutschland herrschen. Auch bezüglich der sozialen Absicherung wird nichts behandelt. Wobei es verständlich ist, dass das letztere niveaumäßig nicht geeignet ist, aber für die anderen Themen gilt diese Entschuldigung nicht.

\subsection{Interpersonale Beziehungen}

Unter interpersonalen Beziehungen werden in GER (2001: 104) verschiedene Bereiche genannt, die zum Teil auch im Lehrbuch abgedeckt wurden.

\subsubsection{Familienstrukturen}

Bezüglich der Familienstrukturen der Deutschen wird direkt kein Wissen vermittelt. Jedoch werden anhand der Dialoge und dem Wortschatz die Familienstruktur und die Begriffe erläutert. Der Dialog bzw. Lückentext in Modul 3A1a (Öztürk et al., 2019: 32) zeigt eine Unterhaltung zwischen zwei deutschen Jugendlichen, die über ihre Familie sprechen. Aus diesem Dialog wird für die Lernenden ersichtlich, dass es in Deutschland ähnliche Familienstrukturen und mehr oder weniger Großfamilien gibt und dass gegen der oftmals herrschenden Ansicht auch Verwandtschaftsbeziehungen aufrechterhalten werden. Doch ist hier zu sehen, dass der Dialog abrupt endet, nach dem einer der Jugendlichen erzählt, dass sein Vater in England lebt. Warum er dort lebt, ob die Eltern Geschieden sind bleibt offen. 


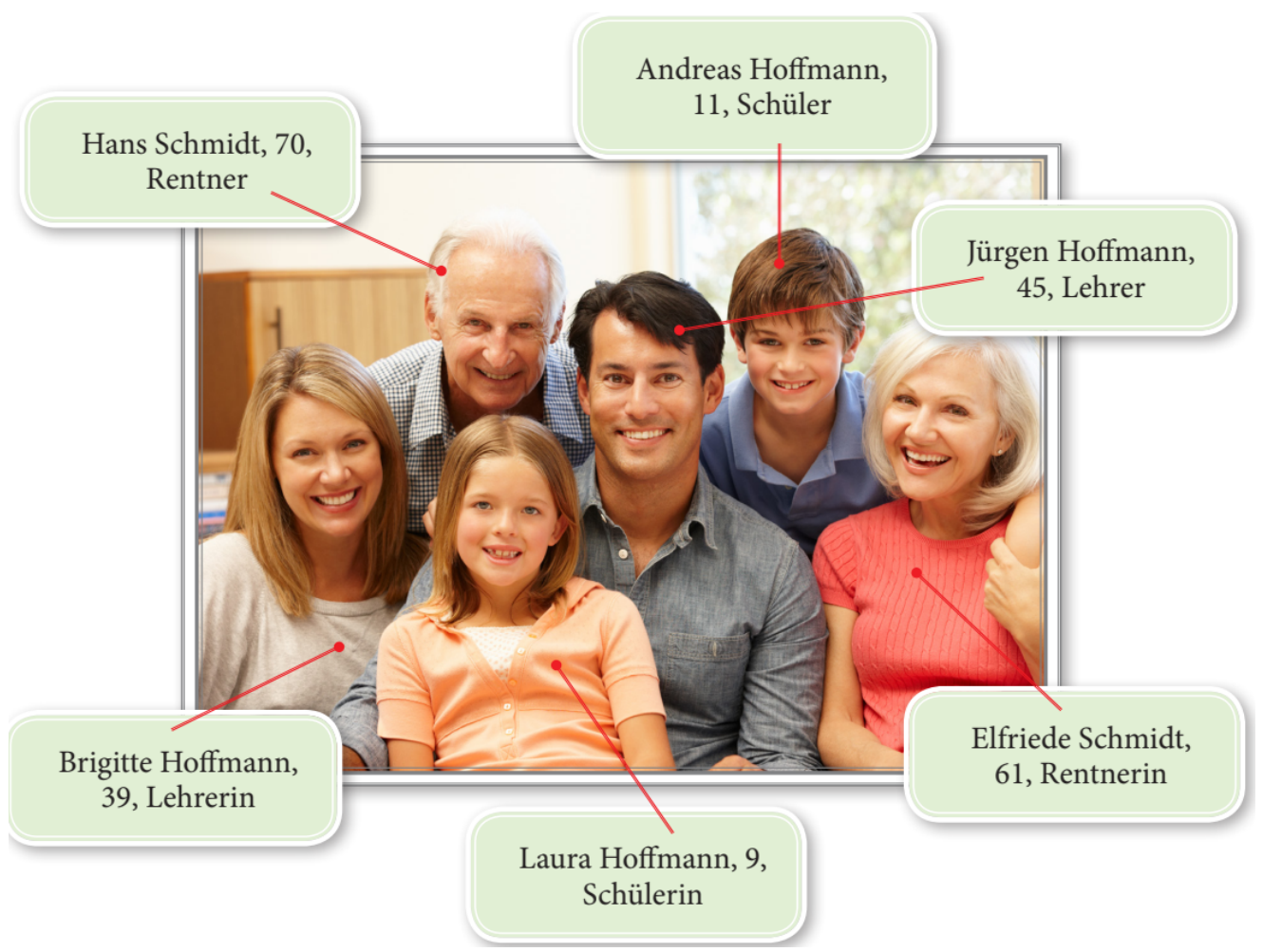

Abb.9 Familienfoto (Öztürk et al., 2019: 34)

Auf dem Foto in Modul 3B1c (Öztürk et al., 2019: 34) ist eine deutsche Familie mit Oma und Opa abgebildet und bietet sowohl separat als auch mit der Übung in Modul 3A2 (Öztürk et al., 2019: 33) eine Vergleichsmöglichkeit über die deutsche und türkische Familienstruktur und die Beziehung zu den Großeltern, wodurch wiederum Gemeinsamkeiten entdeckt werden können.

\subsubsection{Beziehung zwischen den Generationen}

Dass auch unter den Deutschen eine enge Beziehung zwischen Generationen bestehen kann, wird vor allem aus den Bildern wie Modul 3B1c (Öztürk et al., 2019: 34) ersichtlich. Auch wenn hier nicht direkt angesprochen wird, dass auch deutsche eine enge Beziehung zu Großeltern haben, sprechen die Fotos Gemeinsamkeiten mit der türkischen Familie aus. Außerdem wird durch Vermittlung von Konventionen in Unterhaltung (Modul 1A4a, Öztürk et al., 2019: 13) gezeigt, dass ein gewisser Respekt vorhanden ist.

Bezüglich der in GER (2001: 104) genannten anderen Bereiche werden keine Angaben gemacht. Was in Betracht des Niveaus des Lehrbuchs und der Lernenden auch verständlich ist. Ganz im Gegenteil es wäre wohlmöglich ein Fehler gewesen die Lernenden auch mit Informationen aus diesen Bereichen zu überhäufen, da sie zum Teil auch einen erweiterten Wortschatz erfordern.

\subsection{Werte, Überzeugungen und Einstellungen}

Im Lehrbuch werden nur Berufe genannt und nicht weiter auf ihre spezifischen Eigenschaften oder ihren Status eingegangen. Soziale Schichten, regionale Kulturen, Sicherheit, Tradition und sozialer Wandel werden nicht thematisiert. Bezüglich des Sprachniveaus ist dies auch verständlich, weil diese Bereiche höheres Sprachniveau erfordern. Auch Erläuterungen zu Religion, Kunst und Humor sind im Lehrbuch nicht vorhanden.

Bezüglich der Institutionen und Politik sind in den Modulen des Lehrbuchs keine Angaben zu finden. Nur im Teil „Landeskunde“ (Öztürk et al., 2019: 8) wird eine 
Deutschlandkarte mit den Bundesländern angegeben. Auch wenn hierzu nichts erläutert wird, ist wohl für die Lernenden der Unterschied zwischen der Türkei ersichtlich. Bezüglich anderer Länder, Staaten, Völker werden z.B. in Modul 1C „Länder und Sprachen“ (Öztürk et al., 2019: 16) Angaben zu anderen Ländern und Nationen gemacht. In einer weiteren Übung in diesem Modul werden einige Internationalismen behandelt.

\section{Internationalismen}

Welche Wörter kennen Onur, Belinda und Ivan? Schreib sie unter die Fotos!

- Taxi • Gitarre • Bus •CD • Pizza • Hamburger

Abb.10 Internationalismen (Öztürk et al., 2019: 16)

Positiv in dieser Übung ist, dass auch die türkischen Lernenden einige Begriffe erkennen können und sowohl -wenn auch oberflächlich- Gemeinsamkeiten mit Deutschen als auch mit Russen oder Spaniern angesprochen werden. Bezüglich der anderen deutschsprachigen Länder ist im Lehrbuch fast nichts $\mathrm{zu}$ finden. Schweiz und Österreich kommen nur einmal im Fertigkeitstraining von „Modul 1“(Öztürk et al., 2019: 18) vor.

Die oben genannten Informationen im Lehrbuch werden nicht mit den Werten, Überzeugungen und Einstellungen in Beziehung gebracht, stehen eher als lose landeskundliche Informationen.

\subsection{Körpersprache}

Zur Körpersprache, die in GER auch im Abschnitt 4.4.5.2 Paralinguistische Mittel (2001: 91f) behandelt wird, liefert das Lehrbuch nichts Spezifisches. Auf den Fotos sind lächelnde Personen und mehr oder weniger Augenkontakt zu erkennen, die aber den Lernenden nicht weiter auffallen werden. Zum Gebrauch von Sprachlauten ist auch nichts zu finden, obwohl in einigen Dialogen (siehe Abb.11) die Möglichkeit dazu besteht, diese ohne Aufwand nebenbei zu vermitteln.

\subsection{Soziale Konventionen}

\subsubsection{Konventionen und Tabus in Benehmen und Unterhaltung}

In Modul 1 (Öztürk et al., 2019: 12ff) werden bezüglich der Konventionen und Tabus in Benehmen und Unterhaltung den Lernenden verschiedene Begrüßungs- und Verabschiedungsformen vermittelt, deren Nutzungssituation aus den Fotos ersichtlich ist. Im weiteren Verlauf des Moduls werden den Lernenden auch Konventionen bezüglich der Anrede älterer oder fremder Personen nähergebracht. So wird z.B. im Dialog „Wie geht es dir“ (Modul 1A4a, Öztürk et al., 2019: 13) die Funktion von „Sie“ und „du“ veranschaulicht und aus der Kombination mit dem nebenstehenden Foto können die Lernenden erschließen, dass man ältere Personen mit „Sie“ anspricht. 
a Lies den Dialog!

Alina : Guten Tag, Frau Müller!

Frau Müller : Guten Tag, Alina! Wie geht es dir?

Alina : Danke, gut! Wie geht es Ihnen?

Frau Müller : Danke, es geht mir auch gut!

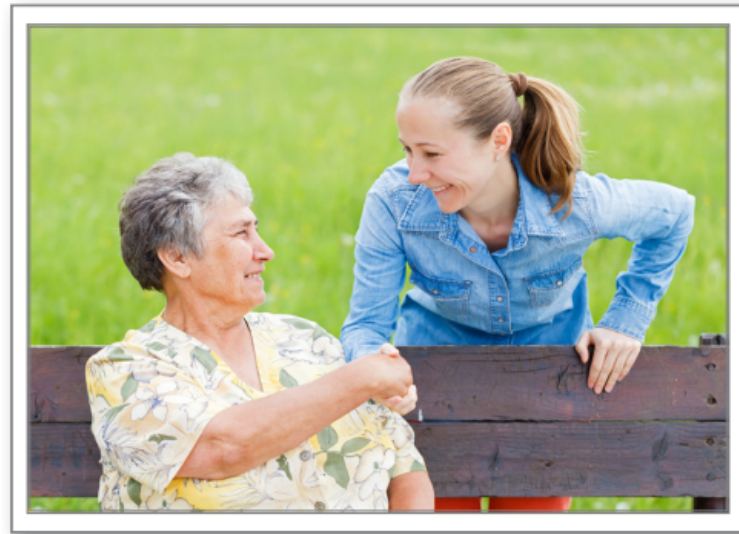

Abb.11 Beispiel zu Konventionen und Tabus in Benehmen und Unterhaltung (Öztürk et al., 2019: 13)

Auch durch Angabe der Antwortmöglichkeiten auf die Frage „Wie geht es dir/Ihnen?“ (siehe Abb.10) werden Wissen vermittelt, um Situationsgemäß und den Konventionen entsprechend seinen Gefühlszustand ausdrücken zu können.

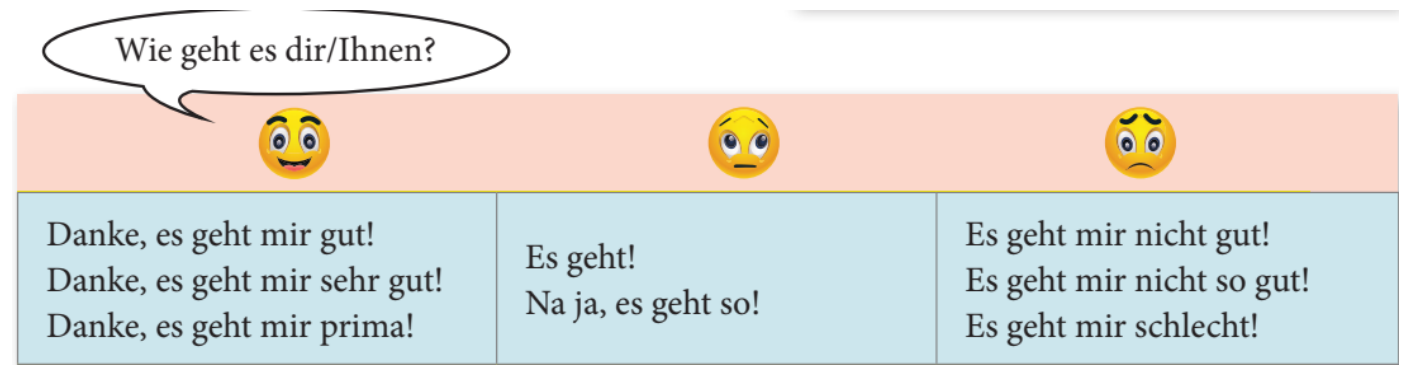

Abb.12 Antwortmöglichkeiten auf,,Wie geht es dir/Ihnen?““(Öztürk et al.: 13)

Weiter werden im weiteren Verlauf der Module auch einige sprachliche Mittel zum Ausdruck von Abneigung und Zuneigung vermittelt. Angesichts des Sprachniveaus sind die Beispiele ausreichend und angemessen.

Bezüglich der Dialoge herrscht jedoch ein Problem, dass sie oftmals plötzlich enden, obwohl sie angesichts der sozialen Konventionen weiterverlaufen müssten, wie aus dem untenstehenden Beispiel zu entnehmen ist. 


\section{Der Kartoffelsalat für die Oma}

a Lies den Dialog und ergänze die Lücken!

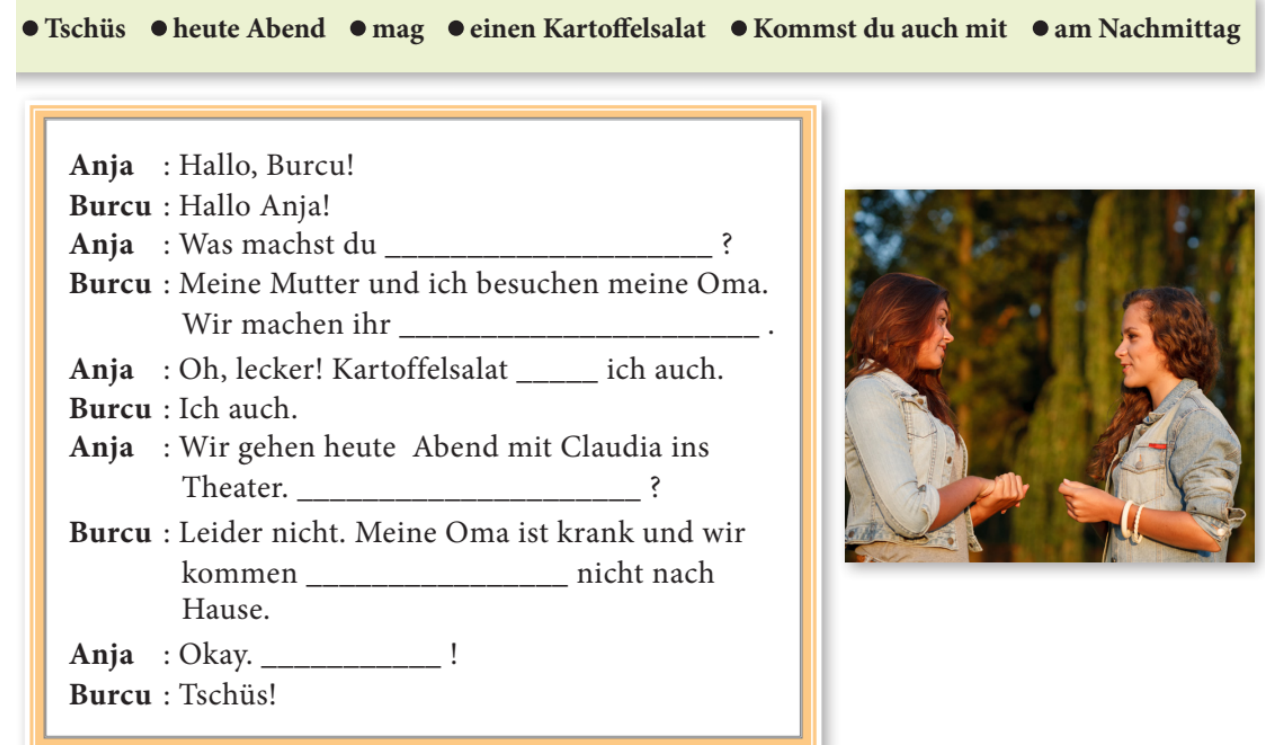

Abb.13 Beispiel zu den Problemen in Unterhaltung (Öztürk et al., 2019: 56)

In dem Dialog unterhalten sich zwei Freundinnen (eine Türkin und eine Deutsche). Die Türkin muss die Einladung ins Theater abschlagen, weil ihre Oma krank ist, woraufhin der Dialog plötzlich endet. Sowohl bei den Türken als auch bei den Deutschen würde man -egal ob man die Person kennt oder nicht- aus Höflichkeit normalerweise ein Mitgefühl aussprechen (z.B. Oh, das tut mir aber leid) oder Besserung wünschen. Hier kann bei den Lernenden ein falscher Eindruck erweckt werden, dass die Deutschen auf so etwas nicht achten oder dass es bei ihnen nicht üblich ist „gute Besserung“ zu wünschen.

\subsubsection{Kleidung}

Die Benennung des Moduls 8B als „Meine Klammotten“ ist doch recht ungewöhnlich, da Klamotten eine saloppe Bezeichnung ist und meiner Ansicht nach nicht unbedingt der erste Begriff sein sollte, dem die Lernenden in diesem Thema begegnen. Die Autoren wollten wohl authentisch klingen, aber meiner Ansicht nach haben sie daneben getroffen. Bezüglich der Kleidung sind besonders aus verschiedenen Fotos im Lehrbuch die Alltagskleidung sowie Berufskleidungen zu erkennen.

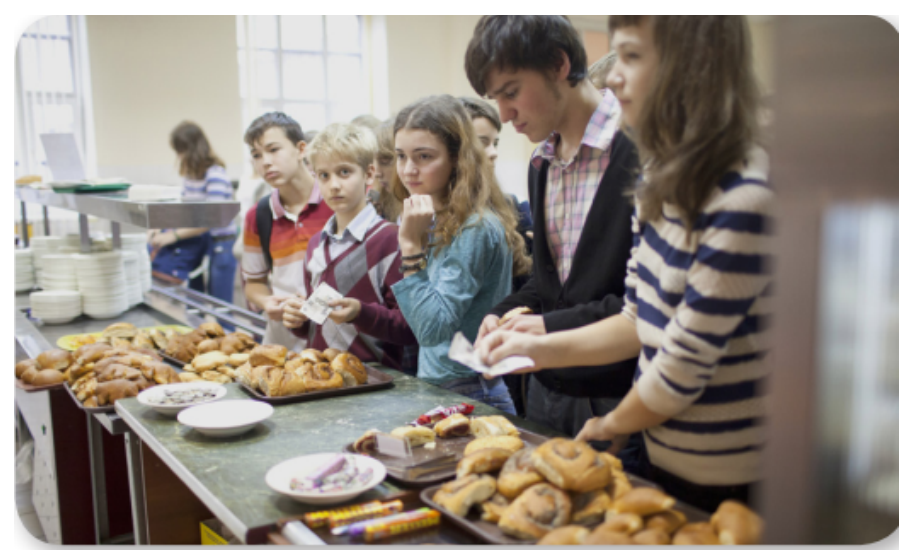

Abb.14 Beispiel aus dem Lehrbuch zur alltäglichen Kleidung (Öztürk et al., 2019: 41) 
Auf dem obigen Bild (Abb. 14) sind Schüler in der Mensa/Kantine zu sehen. Das Bild ist auch einer der wenigen Beispiele, die ein authentisches Flair tragen und ist daher ein gutes Beispiel zur alltäglichen Kleidung.

Das oben angesprochene Modul 8B, das die Kleidung thematisiert, zeigt extravagante Beispiele aus dem Modebereich. Anstelle dieser Sorte von Kleidung könnten -um das Thema effizienter zu behandeln- alltägliche Kleidungen und Kleidungen zu bestimmten Zwecken, wie Sport, Beruf, Feierlichkeiten etc. thematisiert werden.

\subsubsection{Erfrischungen, Getränke, Mahlzeiten}

Die Erläuterungen zu diesem Bereich wurden im Abschnitt „Essen und Trinken, Essenszeiten, Tischmanieren" größtenteils dargelegt. Was aber in beiden Bereichen zu vermissen ist, sind typisch deutsche Gerichte oder Fastfood, die die deutsche Kultur spiegeln, wie Currywurst, Pommes Rot-Weis, Fischfilet mit Spinatrahm oder Getränke wie Apfelsaft anstelle von Orangensaft.

Im Rahmen von sozialen Konventionen ist Interessant, dass im Lehrbuch die größte Tugend der Deutschen also die „Pünktlichkeit“ überhaupt nicht angesprochen wird. Bezüglich der Geschenke wird in Modul 6B1 (Öztürk et al., 2019: 64) Geburtstagsparty und Geschenkarten oberflächlich behandelt. $\mathrm{Zu}$ welchen Anlässen es in Deutschland üblich ist jemandem ein Geschenk zu geben, wird nicht näher behandelt.

\subsection{Rituelles Verhalten}

Bezüglich ritueller Verhaltensweisen der Deutschen wird im Lehrbuch nichts näher vermittelt. So kommt z.B. Weihnachten als Begriff nur einmal vor und nichts Näheres wird vermittelt. Auffallend ist, dass das Lehrbuch mehr türkische als deutsche Feiertage nennt. Wie schon im Abschnitt Feiertage erläutert wurde, schwächelt das Lehrbuch in diesem Bereich. Man sucht vergebens nach anderen besonderen Tagen und den Verhaltensweisen an diesen Tagen, diese werden regelrecht ignoriert. Nur im Fertigkeitstraining Sprechen von Modul 6 (Öztürk et al., 2019: 68) wird den Lernenden ein Hauch der Möglichkeit geboten die Feiertage mehr oder weniger zu verstehen.

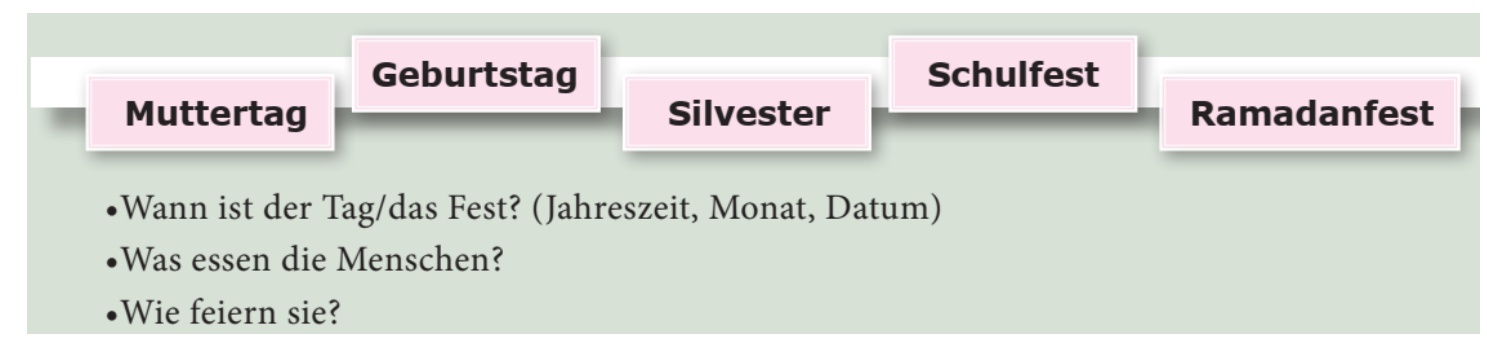

Abb.15 Sprechübung zu Feiertagen (Öztürk et al., 2019: 68)

In der oben abgebildeten Übung sollen die Lernenden anhand der Fragen recherchieren und Informationen zu den Feiertagen sammeln. Jedoch fehlen auch hier wiederum Besondere Tage wie Weihnachten, Tag der Einheit, Rosenmontag, Karneval etc. So ist es auch bei religiösen Bräuchen, Geburt, Heirat etc.

Bezüglich der Verhaltensweisen von Zuschauern bei öffentlichen Veranstaltungen und Zeremonien wird in Modul 8A4a (siehe Abb. 15) ein kleiner Abschnitt behandelt. 


\section{Die Regeln im Park und im Museum}

a Was darf man/darf man nicht und was muss man im Park oder im Museum machen! Sprecht in der Klasse!

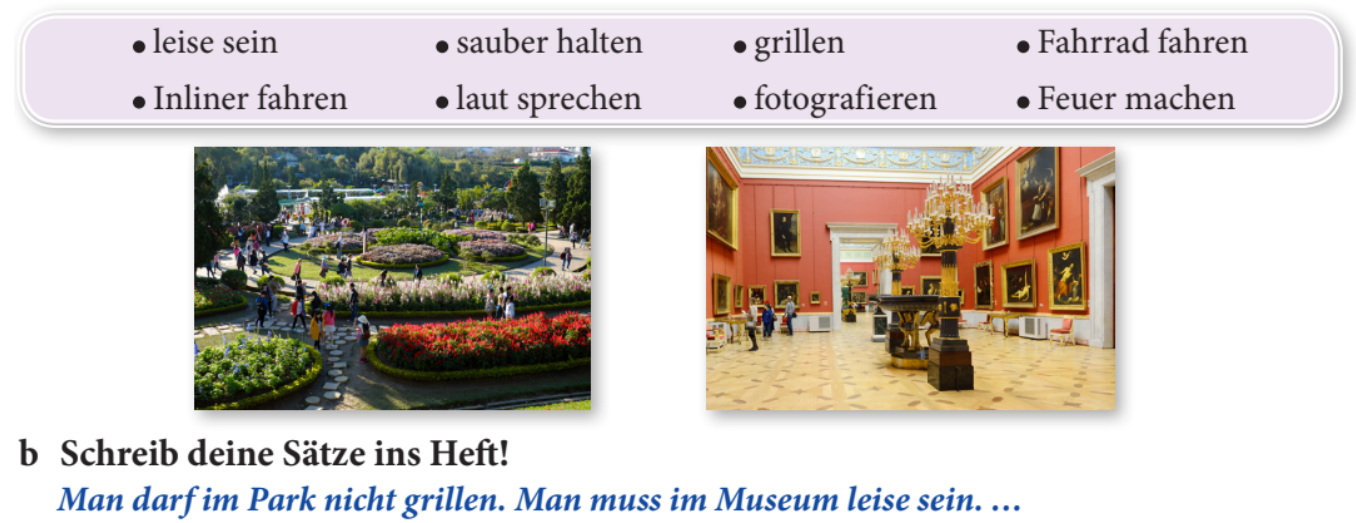

Abb.16 Beispiel zum Verhalten in der Öffentlichkeit (Öztürk et al., 2019: 83)

In der oben dargestellten Übung sollen die Lernenden erlaubte und verbotene Verhaltensweisen $\mathrm{zu}$ den angegebenen Orten wählen. Dadurch können sie in Sachen Verhaltensnormen Gemeinsamkeiten und Unterschiede zu ihrem Land erkennen.

Ein positiver Punkt bezüglich des Lehrbuchs ist, dass verschiedene deutsche Namen vorkommen und das Klischee von „Helga und Hans“ gebrochen werden kann.

\section{SCHLUSSFOLGERUNG}

Zweck der Vermittlung von soziokulturellem Wissen ist es die Zielkultur zu verstehen, mit seiner eigenen Kultur zu vergleichen und somit eine positive Haltung gegenüber der zu erlernenden Zielsprache zu entwickeln und folglich einen positiven Effekt im Lernprozess zu erzeugen. Angesichts der Situation, in der sich $\mathrm{DaF}$ als Zweitfremdsprachenunterricht befindet, des Sprachniveaus, dem sich das Buch richtet, können wir sagen, dass „Wie bitte? A1.1“ einigermaßen gut abschneidet. Besonders in einigen Bereichen wie das tägliche Leben, Freizeitbeschäftigungen und Hobbys, Beziehungen zwischen Generationen, Kleidung, Konventionen und Tabus in Benehmen und Unterhaltung gibt das Buch ausreichende Beispiele. Die Vermittlung der soziokulturellen Elemente verläuft vorwiegend im Hintergrund und auch anhand der Fotos werden Sprech- und Diskussionsanlässe geliefert. Diese zu bemerken und zu nutzen steht in der Verantwortung des Lehrers, was uns zu einem großen Mangel des Lehrwerks führt nämlich, dass es kein funktionsmäßiges Lehrerhandbuch hat. Das vorhandene Lehrerhandbuch ist nichts weiter als ein Lösungsschlüssel zu den Übungen. So entsteht die Gefahr, dass diese Informationen und Sprechanlässe, die zur Bewusstmachung der soziokulturellen Elemente, zum Vergleich beider Kulturen wichtig sind, übersehen werden.

Bezüglich der Fotos ist man bei der Analyse davon ausgegangen, dass sie aus Deutschland stammen bzw. deutsches präsentieren also z.B. ein deutsches Klassenzimmer abgebildet ist. Doch die Tatsache, dass als Quelle der Fotos ,www.shutterstock.com“ angegeben ist, lässt doch an dieser Annahme zweifeln, zu dem noch wenig authentisches in ihnen zu finden ist. Die Fotos erscheinen zu sehr inszeniert und es mangelt häufig an authentischen Abbildungen. In Bezug auf die Vermittlung von soziokulturellem Wissen ist der Mangel authentischer Bilder und Texte ein großes Defizit, da authentische Materialien per se für die Vermittlung dieser Elemente sehr geeignet sind, weil sie auch der Zielkultur entstammen und ein Produkt dessen sind.

Besonders kritisch zu bemerken ist, dass bezüglich Feste und Feiertage, regionale Kulturen in Deutschland oder kulturell geprägtem Essen wenig zu finden ist. Wir sehen, dass 
das Lehrbuch sich im Thema „Feste und Feiertage“ mehr auf die türkische Kultur konzentriert und keine Vergleichsmöglichkeit zu Festen und Feiertagen, rituellen Verhaltensweisen zur deutschen Kultur bietet. Ein weiteres Negativ ist bezüglich der Dialoge zu nennen. Davon abgesehen, dass sie sehr künstlich und mechanisch aufgebaut sind, ist zu erwähnen, dass auch Konventionen verletzt werden (Siehe Abschnitt „Soziale Konventionen“ \& Abb.13). Ein weiterer Kritikpunkt ist, dass im Bereich deutsche Kunst, Künstler, Literatur und Humor im Lehrbuch keine Beispiele oder Informationen geliefert werden.

Im Allgemeinen wird kein explizites Wissen in allen Bereichen geliefert und auf den ersten Blick erscheint das Lehrbuch recht oberflächlich und ignorant in Sachen soziokulturellem Wissen. Ein näherer Blick zeigt, dass doch im Hintergrund Informationen geliefert werden, deren Entschlüsselung allein vom Lernenden aus nicht möglich erscheint und der didaktischen Qualifikation des Lehrers überlassen wird. Wenn man bedenkt, dass dieses Lehrbuch auch für die Fernschule (açık öğretim lisesi) vorgesehen ist, ist dieser Umstand ein großes Problem, da das Lehrwerk nicht in der Lage erscheint die fehlende Präsenz eines Lehrers zu kompensieren.

„Wie bitte? A1.1“ ist ein so zu sagen länderspezifisch erstelltes Lehrwerk. D.h. es wurde speziell für türkische Schüler, die Deutsch als Zweitfremdsprache in der Türkei lernen verfasst. Länder spezifisch verfasste Lehrwerke bringen im Gegensatz zu international konzipierten Lehrwerken einige Vorteile mit sich. Sie können sich gezielter auf herrschende Probleme im Fremdsprachenerwerb des jeweiligen Landes konzentrieren und zu deren Lösung beitragen. Dieser Umstand gilt besonders auch für den soziokulturellen Bereich. Im Ausgangsland herrschende Missverständnisse, Vorurteile gegenüber der zu erlernenden Zielsprache und dessen Kultur können, gezielter angegangen und (wenn nötig auch in der Muttersprache) erklärt bzw. geklärt werden. Es können Vergleichsmöglichkeiten anhand soziokulturelle Elemente, die auch im Türkischen ähnlich sind, geboten werden z.B. beim Thema Essen „Maultaschen vs. Mant1“, rituelles verhalten an Feiertagen, Lebensbedingungen etc. In dieser Hinsicht wird in „Wie bitte? A1.1“ versäumt in den jeweiligen Themenkreisen die notwendigen Informationen zu liefern oder anhand von Übungen, Aktivitäten zur Klärung vorhandener Missverständnisse zu verhelfen (z.B. Weihnachtsbaum/Neujahrsbaum, Weihnachtsmann/Christkind/Nikolaus). Wobei auch zu bemerken ist, dass im jeweiligen Lehrwerk gezielt religiöse, politische Themen vermieden wurden.

\section{LITERATURVERZEICHNIS}

Balc1, U. (2016). Anadolu liselerinde ikinci yabancı dil olarak Almanca eğitimi: Batman ili örneği. Dicle Üniversitesi Ziya Gökalp Eğitim Fakültesi Dergisi, 29, 346-355. https://doi.org/10.14582/duzgef.757

Cuma, F.I. (2009). Transkulturelle Kompetenz und Landeskunde in den regional erstellten DaF-Lehrwerken in der Türkei. Selçuk Üniversitesi Edebiyat Fakültesi Dergisi, 22, 87-99.

Deutscher Wanderverband (2018, Dezember). Wir über uns. https://www.wanderverband.de/conpresso/_rubric/index.php?rubric=Verband+Wirueber-uns

Europarat-Rat für kulturelle Zusammenarbeit. (2001). Gemeinsamer Europäischer Referenzrahmen für Sprachen: lernen, lehren, beurteilen (GER). (Übersetzt von: J. Quetz, R. Schieß, U. Sköries, G. Schneider) Berlin: Langenscheidt.

Kırmızı, B. (2009). Etkili bir Almanca öğretimi için öğretmen beklentileri. Balıkesir Üniversitesi Sosyal Bilimler Enstitüsü Dergisi, 12(22), 268-280. 
Koçak, M. (2014). “Toko- Demo" adlı Almanca ders kitabında ülke bilgisi. 21.Yüzyılda Eğitim ve Toplum Eğitim Bilimleri ve Sosyal Araştırmalar Dergisi. 3(9), 29-41. https://doi.org/10.20860/ijoses.634150

Köşker, G. (2015): Yabancı dil öğretiminde kültür aktarımı: Fransız dili örneği. Ahi Evran Üniversitesi Kırş̧ehir Eğitim Fakültesi Dergisi (KEFAD), 16(2), 409-421. https://doi.org/10.1501/egifak_0000000796

Maden, S. S. \& Kula, T., Çalışkan, C. (2017). Schritt für Schritt Deutsch ortaöğretim A1.1 düzeyi Almanca ders kitabının kültürlerarasılık bağlamında incelenmesi ve değerlendirilmesi. Diyalog, 2, 121-143. https://doi.org/10.7827/turkishstudies.13412

Marques-Schäfer, G., Filho, E., \& Stanke, R. (2016). Was können Lehrwerke zur Reflexion von Stereotypen im DaF-Unterricht beitragen? Eine Analyse anhand der Arbeit mit DaF kompakt in Brasilien, Informationen Deutsch als Fremdsprache, 43(5), 566-586. doi: https://doi.org/10.1515/infodaf-2016-0506

Memiş, M.R. (2016). Yabancı dil öğretiminde eğitim ortamı ve kültür aktarımı. Turkisch Studies, 11(9), 605-616. DOI Number: http://dx.doi.org/10.7827/TurkishStudies.9506

Milli Eğitim Bakanlığı (MEB), (2018), Orta Öğretim Almanca (Hazırlık,9,10,11ve 12 Sinıflar) Öğretim Programı. http://mufredat.meb.gov.tr/ProgramDetay.aspx?PID=333

Mohammed, A. I. A. (2019). Kulturvermittlung durch Bilder im landeskundlichen DaFUnterricht für sudanesische Deutschlernende 1. Einleitung. Abgerufen von https://www.researchgate.net/publication/331745082_Kulturvermittlung_durch_

Bilder_im_landeskundlichen_DaF-Unterricht_fur_sudanesische_Deutschlernende_1 _Einleitung. https://doi.org/10.37307/j.2198-2430.2008.02.06

Nebe-Rikabi, U. (1997). Authentische Texte im Fremdsprachenunterricht. In: Bickes, G., Dufeu, B., Willkop, E.M. (Hrsg.) Umgang mit Texten-UnterrichtsbeobachtungGrammatikmodelle und ihre Umsetzung in Lehrwerken (Jahrbuch Sprachandragogik 1995), Johannes Gutenberg-Universität Mainz (6-13). http://www.scribd.com/doc/ 27678671/Authentische-Texte-Im-Fremdsprachenunterricht

Öztürk, D., Incebel, F., Balkan, F., Y1ldırım, T., Canoğlu, Y. (2019). Wie Bitte? A1.1 Lehrbuch. Ankara: MEB Yayınları.

Saraç, S. \& Arıkan, A. (2010). Yabancı dil ders kitaplarında hedef kültür bilgisini incelemede kullanılabilecek kontrol listesi uygulamas1. Hitit Üniversitesi, Sosyal Bilimler Enstitüsü Dergisi. 3 (1-2), 45-56. https://doi.org/10.29029/busbed.492135

Storch, G. (2009). Deutsch als Fremdsprache, Eine Didaktik (9. Auflg.). Paderborn: UTB.

Tomková, I. (2007): Landeskunde und ihre Stellung in Lehrwerken für Deutsch. Masaryk Üniversitesi Doktora Tezi. Masaryk Üniversitesi. Bruno.

Typisch deutsch: Fußball, Bier und Wandern? (2017, 10. August). Abgerufen von: http://deutschamerikanischefreundschaft.de/typisch-deutsch-fussball-bier-und-wandern/

\section{GENIŞLETILMIŞ ÖZ}

Yabancı dil öğretiminde istenilen düzeyin elde edilememesi beraberinde yeni yöntemsel arayışlar ve bakış açıları getirmiştir. Eskiden yabancı dilin dilbilgisi öğretimi ve gerekli görülen kalıpların aktarımı vasıtasıyla gerçekleşebileceği kanısı, günümüzde iletişimsel ve kültürlerarasılık boyutunun ağır bastı̆̆ı akımlara yerini bırakmıştır. Öğretilmek istenilen yabancı dilin, bir toplumun ve dolayısıyla da o kültürün ayrılmaz bir parçası olduğu ve dilin de bu toplumun kültüründen, bu kültürün gelişim ve değişiminden etkilendiği gerçeği yabanc1 dil 
öğretiminde de yer etmiştir. Diller için Avrupa Ortak Başvuru Metninde de bu boyuta değinilmekte ve kültürel yeterlilik ile kültürlerarası bilincin geliştirilmesi konusu vurgulanmaktadır. Herhangi bir Avrupa toplumu ve kültürünün özelikleri Diller için Avrupa Ortak Başvuru Metninde şu şekilde sıralanmaktadır:

1. Günlük yaşam

2. Yaşam koşulları

3. Kişiler arası ilişkiler

4. İnançlar ve tutumlar

5. Beden dili

6. Sosyal gelenekler

7. Geleneksel davranışlar

Makalede Milli Eğitim Bakanlığının ikinci yabancı dil Almanca için hazırlatmış olduğu ve yaygın şekilde kullanılan ders kitabı „Wie bitte? A1.1“ yukarıda sıralanmış olan ana başlıklar ve bunların içerisinde yer alan alt başlıklar açısından incelenmiş ve sosyokültürel öğeler açısından hangi noktaların ders kitabında yer aldığı tespit edilmeye çalışılımıştır.

Yapılan inceleme sonucunda "Wie bitte? A1.1" nin hedeflediği dil düzeyi ve ikinci yabancı dil dersi olarak Almancanın Türkiye'de bulunduğu konum da göz önüne alındığında "günlük yaşam, hobiler, aile yapıları ve ilişkileri, nesiller arası ilişkiler, giyim, davranış ve sohbet kuralları" açısından yeterli düzeyde sosyokültürel öğelere yer verildiği ancak işleniş şekli açısından ise bazı noktalarda yetersiz kaldığı kanısına varılmıştır. "Wie bitte? A1.1"de doğrudan bir bilgi aktarımı, yani "Almanlar şöyle davranır, Almanlar şunu yapar" gibi açıklamalar yer almamakla beraber sosyokültürel öğeler, konular içerisinde arka planda, metin, alıştırmalar ve yer verilen fotoğraflar vasıtasıyla aktarılmaya çalışılmakta ve bu konular üzerinde karşılaştırma ve konuşma imkânı sunulmaktadır. Kitabın genelinden de görülebildiği gibi, bu öğelerin tespiti ve konulaştırılması neredeyse tamamen öğretmenlere bırakılmıştır. Sosyokültürel öğelerin aktarımının arka planda gerçekleştirilmesi olumlu bir yaklaşım olarak değerlendirilebilir, ancak işlevsel bir öğretmen el kitabının bulunmaması büyük bir eksikliktir. Mevcut öğretmen el kitabı sadece alıştırmalara ilişkin çözümleri içermekte, dersin veya konuların işlenişi ile ilgili öneri veya ipuçları, alternatif yaklaşım şekilleri, önemli noktalara dikkat çeken açıklamalar yer almamaktadır. Bu yükün sadece öğretmenin bu konudaki bilinç, bilgi ve becerilerine bırakılması önemli bir eksikliktir ve sosyokültürel öğelerin aktarımında belirli bir standarda ulaşılmasını da zorlaştırmaktadır. Ayrıca söz konusu ders kitabının açık öğretim lisesinde de kullanılıyor olması kitaba ayrı bir sorumluluk yüklemekte ve öğretmen eksikliğini giderebilecek bir yapıda olması koşulunu beraberinde getirmektedir. "Wie bitte? A1.1" bu noktada yetersiz kalmaktadır.

Önemli tespitlerden bir tanesi de konular içerisinde Alman kültürü ve toplumu açısından hâkim olan basma kalıp düşüncelerin ve yanlış bilgilerin giderilmesine yönelik öğelerin yeterince konu edilmemiş olması, Modüllerin konu itibariyle sundukları firsatların değerlendirilmemiş olmasıdır. Özellikle dini ve özel günler bakımından ders kitabı çoğunlukla Türkiye'ye odaklanmakta daha çok Türkiye'deki özel gün ve bayramları işlemektedir. Örneğin yılbaşı ile Noel'in karıştırılması veya bir tutulması, Türkiye'de yeni yıl ağacı diye kullanılan esasında Noel'in öğesi olan ağaç ve süslemelere ilişkin bilgilendirme ve yanlışı düzeltmeye yönelik bir aktarım yapılmamaktadır.

Kitabın hedeflediği düzey açısından bakıldığında azınlık, din, politika, sosyal güvence, tarih gibi konuların işlenilmemiş olması anlaşılır hatta olumlu olarak değerlendirilebilir. Ancak ders kitabında sanat, sanatçılar, edebiyat ve mizah gibi alanlara ilişkin herhangi bir öğeye de yer verilmemekte hatta Almanların en büyük erdemi olarak sayılan dakiklik konusu da işlenmemektedir. 
"Wie bitte? A1.1"de yer verilen fotoğraflara ve metinlere/diyaloglara bakıldı̆̆ında özgün materyal eksikliği göze çarpmaktadır. Sosyokültürel öğelerin aktarımı açısından özgün materyallerin çok uygun olması nedeniyle bu büyük bir eksiklik olarak değerlendirilmektedir. Bunun dışında diyaloglar açısından bakıldığında sosyal kurallar bakımından da bazı aykırı durumların olduğu söylenebilir, örneğin 56. sayfada yer alan diyalogda biri Alman diğeri Türk olan Anja ve Burcu isimli iki arkadaşın sohbetine yer verilmiştir. Anja, Burcu'yu tiyatroya davet etmekte ancak Burcu anneannesi/babaannesinin hasta olduğunu gelemeyeceğini ifade ettikten sonra diyalog birden sona ermektedir. Davranış normları açısından baktığımızda Almanlarda da üzüntüsünü ifade etme, geçmiş olsun dileme gibi davranış şekilleri ve kalıplar mevcuttur. $\mathrm{Bu}$ durum öğrencilerde yanlış bir kanı ve kısmen de hâkim olan "Almanlar umursamazdır, nezaketsizdir" görüşünü güçlendirebilecek olumsuz bir etki yaratabilir. Burada basit bir şekilde diyaloga iki satır ekleyerek hem bu kalıpların hem de sosyokültürel öğelerin aktarımı sağlanabilecekken bu firsat kullanılamamıştır. Fotoğraflarda da benzer sorunlar karşımıza çıkmaktadır. Örneğin 42. sayfada günlük akış konusu işlenirken kahvaltı resminde tipik bir Alman kahvaltısı yerine Amerikan kahvaltısı diye adlandırılan türde bir kahvaltının fotoğrafına yer verilmiştir. Aynı şekilde Alman kültürüne özgü bir kavram olan "Abendbrot" kavramına ilişkin fotoğrafta geleneksel bir "Abendbrot" öğününü gösteren fotoğrafa yer verilmemiş olması ve yerine kullanılan fotoğrafin bu kavramın anlamını ve içeriğini yansıtacak boyutta olmaması bir eksikliktir.

Daha önce ifade edildiği gibi "Wie bitte? A1.1" Milli Eğitim Bakanlığı tarafından hazırlatılmış ve Türk öğrencilere yönelik bir kitaptır. Ulusal düzeyde belirli bir gruba göre hazırlanmış bu tür kitapların esasında uluslararası bir kitleye göre hazırlanmış kitaplara göre belirgin bir avantajı vardır. Çünkü belirli bir hedef gruba göre hazırlandıkları için, o grubun kültürü ve hedef dil kültürü ile toplumu arasındaki ilişkilere yönelik konular daha rahat işlenebilmektedir. Kaynak kültürde hedef kültüre ilişkin basmakalıp düşünce ve yanlış anlamaların ortadan kaldırılması, iki kültür arasındaki benzerliklerin, farklılıkların ortaya koyularak karşılaştırmaların yapılması ve hedef dil ile kültürüne yönelik olumlu tutum ve düşüncelerin geliştirilmesi daha kolay olabilmektedir. "Wie bitte? A1.1"yi bu açıdan değerlendirdiğimizde potansiyelin yeterince kullanılmadığını hatta konular içerisinde basit bir şekilde aktarım firsatı doğan birçok öğenin gözden kaçırıldığını veya çeşitli çekinceler sebebiyle yer verilmediğini söyleyebiliriz. 